\title{
Misión Sangley. La cristianización entre los chinos de Filipinas en el cambio del siglo XvI al XVII
}

\section{Sangley Mission. Christianization of the Philippines' Chinese in the turn of the Sixteenth to the Seventeenth Century}

Resumen: El mundo chino se expandió más allá de las fronteras imperiales gracias al desarrollo de un espacio portuario con dinámicas distintas a las de las provincias del interior. Redes de comerciantes, migrantes y piratas, a la vez que los intereses imperiales y una gran variedad de ideas estuvieron en movimiento constante en todo el Sudeste Asiático y gran parte del mundo Pacífico. En Filipinas, esta situación permitió a los misioneros católicos españoles trabajar con chinos o sangleyes antes del ingreso a China. ¿Qué representó para la Misión China? ¿Qué dinámicas misionales se desarrollaron entre los chinos o sangleyes? ¿Se puede hablar de una Misión Sangley?

Palabras clave: patronato español; colonialismo; imperialismo; mendicantes; sangleyes.

Abstract: The Chinese world expanded beyond its imperial borders thanks to the development of a port area with a different social dynamic than what was found in the provinces in the empire's interior. Networks of merchants, migrants, and pirates, along with agents

Recepción: 26 de octubre de 2016. / Aceptación: 25 de abril de 2017.

* Universidad de Costa Rica, ricardo.martinezesquivel@ucr.ac.cr 
defending the imperial interests and its ideas, were in constant movement throughout Southeast Asia and much of the Pacific region. In the Philippines, this situation allowed Spanish Catholic missionaries to work with Chinese or Sangleys before entering China. What did this situation represent for the China Mission? What kind of missionary dynamics developed between the Chinese or the Sangleys? Can we talk about a Sangley Mission?

Kew words: Spanish Patronage; colonialism; imperialism; mendicants; Sangleys.

El encuentro entre China y los misioneros españoles se desarrolló como parte de una historia transoceánica entre los mundos Atlántico y Pacífico, cuyo eje relacional lo ejerció Nueva España, base a su vez del envío de misioneros, correspondencia y fondos a la Misión China. En este contexto, Filipinas, como su extensión colonial, se constituyó en el punto de llegada de quienes estuvieron con la mirada puesta en China.

Se debe tener claro que muchas de las personas que llegaron a Nueva España a raíz de la conquista, lo hicieron inspiradas por los relatos de paraísos y riquezas, desde Il Milione de Marco Polo hasta la Historia de las cosas más notables, ritos y costumbres del gran Reyno de la China de Juan González de Mendoza. Por consiguiente, la identificación de una ruta por el mundo Pacífico hasta el oriente de Asia se consideró clave para continuar con la empresa comercial de China, objetivo primero, si no principal, de esta etapa inicial de expansión de la modernidad. Por ello, muy conscientes de esto, y cuando se tuvo total claridad del recorrido del tornaviaje de Andrés de Urdaneta, circuló una carta con la frase: "Y los de México están muy ufanos con su descubrimiento; que tienen entendido que serán ellos el corazón del mundo [al conectar Europa con China]". ${ }^{1}$ En definitiva, en todos los niveles sociales europeos

1 "Copia de vna carta venida de Seuilla a Miguel Saluador de Valencia. La qual narra el venturoso descubrimiento que los Mexicanos han hecho, nauegando con la armada que su Magestad mando hazer en Mexico. Con otras cosas marauillosas, y de gran prouecho para la Christiandad; son dignas de ser vistas y leydas", en Patricio 
se consideró a China como eje de lo que podría funcionar como un mercado global, el nodo principal de un verdadero sistemamundo. Así, los españoles vieron en Filipinas la vía de acceso, sin imaginar que, más bien, encontrarían una ampliación del mundo chino. ¿Qué representó esta situación para la Misión China? ¿Qué dinámicas misionales se desarrollaron entre los chinos o sangleyes? ¿Se puede hablar de una Misión Sangley?

\section{II}

La conquista española de Filipinas vino de la mano del agustino Miguel López de Legazpi, con el establecimiento colonial durante 350 años. Encargado por el rey de España Felipe II de asegurar posiciones en el mundo Pacífico y de encontrar un nuevo camino a las islas de las especias, Legazpi zarpó de Nueva España siguiendo la ruta de Fernando de Magalhães a Cebú y avanzando lentamente hacia el norte, a la isla de Luzón. Legazpi conquistó (1565) y reclamó las islas en nombre de su rey.

Pronto, con el inicio de la colonización española se hizo necesaria su organización administrativa. En términos civiles se le consideró una extensión colonial de Nueva España, así que se creó la Capitanía General de las Islas Filipinas, pero en términos religiosos, una bula pontificia la dejó bajo la jurisdicción eclesiástica del obispado de Goa en el Estado Português da Índia. El obispado de Goa había sido organizado en 1530, un año después del Tratado de Zaragoza y con jurisdicción desde el este de África hasta Japón, por lo que todo lo conquistado por los españoles en Asia quedaría, en términos religiosos, bajo el padroado portugués. Con los portugueses llegaron los jesuitas, quienes paulatinamente se expandieron desde Goa hasta Macao y Nagasaki.

Al parecer, hubo una alianza tácita entre la Corona portuguesa y la Compañía de Jesús, ${ }^{2}$ aprovechando las bulas pa-

Hidalgo Nuchera (ed.), Los primeros de Filipinas. Crónicas de la conquista del archipiélago, Madrid, Miraguano Ediciones/Ediciones Polifemo, 1995, pp. 210-212.

2 Paulina Numhauser, "El Real Patronato en Indias y la Compañía de Jesús durante el período filipino (1580-1640). Un análisis inicial”, Boletín Americanista, núm. 67, 2013, p. 90. 
pales que le otorgaron el monopolio misional en toda Asia -al menos hasta 1633-, el padroado y la obligación de patrocinio por parte de Portugal. A su vez, la Corona española estableció un estrecho vínculo con las órdenes mendicantes. Más tarde, ellas también llegaron a Goa y al espacio portugués.

Los portugueses no quisieron perder esta oportunidad de inmiscuirse en los planes españoles, y en 1576 se erigió la diócesis de Macao, sufragánea de Goa y con jurisdicción en China, Japón y Filipinas. En un juego de balance del poder político, sin embargo, España logró que Roma accediera a la creación de la diócesis de Manila en 1578, dependiente de la iglesia novohispana. Más tarde, la anexión de la Corona portuguesa al reinado de Felipe II llevó a la organización de la Audiencia de Manila (1583), cuya jurisdicción incluyó a China, que hasta ese momento se encontraba en la órbita colonial portuguesa.

En este proceso de consolidación de los poderes civil y religioso en Filipinas llegaron las órdenes misioneras. Los agustinos lo hicieron con la conquista misma, en 1565, luego los franciscanos en 1578, los jesuitas en 1581 y, por último, los dominicos en $1587 .{ }^{3}$ Los misioneros organizaron sus propias provincias, iniciaron sus intentos de penetración en China y, finalmente, tal vez sin haberlo planeado, establecieron la Misión Sangley. Éste fue el inicio, por parte de los españoles, de la inscripción de la fe católica por medio de un imperio transpacífico dependiente de la travesía oceánica llamada "el Lago español".

Los españoles vieron en Filipinas la vía de acceso no sólo a las riquezas chinas, sino a las de toda $\mathrm{Asia}$. $\mathrm{Al}$ respecto escribió el maestre Mateo del Saz a Felipe II:

[...] es la mejor puerta que en todas estas partes ay para conseguir lo que Vuestra Magestad pretende para lo de adelante, así para la especería del Maluco [como para] Burney, Luzon, Costa de la China, Malaca, Samatra, Japón, Lequios, Java mayor y menor, Míaos, Pantan, Sian y

${ }^{3}$ José Antonio Cervera, Tras el sueño de China. Agustinos y dominicos en Asia Oriental a finales del siglo XVI, Madrid, Plaza y Valdés, 2013. Eduardo Descalzo Yuste, “'Las misiones más trabajosas, y difíciles, que tiene la universal Compañía'. Dificultades de la labor misional de la Compañía de Jesús en Filipinas (1581-1768)”, Revista Estudios, núm. 32, 2016, pp. 467-495. 
otras riquísimas tierras e rreynos abundantes artos de rriquezas e contrataciones. ${ }^{4}$

No obstante, los españoles encontraron en sus planes cuatro inconvenientes: la magnitud del imperio Ming, nunca dimensionada; la reticencia china a comerciar debido a la ignorancia europea de la lógica ritualista de su sistema de relaciones tributarias; la competencia imperialista portuguesa y luego holandesa; y los territorios controlados por los sultanatos. Poco a poco se diluyó el proyecto de conquista, el cual coincidió con el hundimiento de la Armada Invencible; para empezar lo rechazó el primer obispo de Filipinas, el dominico Domingo de Salazar, y luego la Compañía de Jesús, que estaban preocupados de que éste boicoteara los avances de la Misión China realizados por Matteo Ricci.

Las relaciones españolas con China desde Filipinas, durante la segunda mitad del siglo XVI, se restringieron a las provincias costeras del sur de Zhejiang, Guangdong y Fujian. A pesar de la dinámica centralizadora del poder Ming, el imperio nunca se comportó como una entidad global única. Regiones alejadas de la capital, como las señaladas, participaron de una dinámica comercial y mercantil, legal e ilegal, regional e supranacional, más allá de las políticas administrativas imperiales. Esto lo tuvo claro el gobierno central, por lo que en 1567 , iniciando el reinado el emperador Longqing 隆慶, se aprobó el kaihai 開海o política de apertura marítima, la cual relajó las prohibiciones del mar de la anterior haijin 海禁. ${ }^{5}$ Por consiguiente, se está ante la construcción de un espacio portuario chino con una dinámica e identidad propias y distintas en muchos aspectos a las provincias del interior. Esto explica parte de la futura inserción e integración de los misioneros en China.

En particular, desde estas provincias el mundo chino se extendió por todo el Sudeste Asiático, incluidas las Filipinas,

\footnotetext{
${ }^{4}$ Nota reproducida en Pablo Pastells, "Intentos y conquistas en el Extremo Oriente y competencias habidas con los portugueses sobre la posesión de las regiones situadas fuera del empeño, antes de la unión de las dos Coronas", ponencia presentada en el II Congreso de Historia y Geografía Hispanoamericanas, Sevilla, 1921, p. 369.

${ }^{5}$ Manel Ollé, La empresa de China. De la Armada Invencible al galeón de Manila, Barcelona, Acantilado, 2002, pp. 12-23.
} 
donde hasta el siglo XVIII los chinos siempre fueron mayoría. ${ }^{6}$ Este proceso de diáspora mercantil china se explica por tres factores: un aumento demográfico a mayor velocidad que el crecimiento económico; vías de comunicación marítimas por excelencia con otras provincias chinas, lo cual, al menos desde Fujian, facilitó el movimiento hacia otras regiones de ultramar; y el fracaso de las políticas imperiales contra el comercio extranjero. ${ }^{7}$ A esto se deben sumar las dinámicas de las redes familiares chinas en clanes-empresa, gongsi, dispersos pero conectados, desde Fujian y por todo el Sudeste Asiático. Estas redes comerciales y de confianza tejieron conexiones a gran escala entre China y los mundos Índico y Pacífico.

En el caso de los españoles en Manila, a los pocos años de haber llegado dieron cuenta y razón del asentamiento de una comunidad china gracias al flujo comercial desde Fujian. En 1572, Juan Pacheco Maldonado escribió al respecto:

[...] bienen cada año a la dicha çiudad de Manila doze y quinze navíos de tierra firme de la China, cargados de mercadurías, sedas labradas de todas suertes, trigo, harina, azucar, muchos géneros de frutas, hierro, azero, estaño, latón, cobre y plomo, y otros géneros de metales, y todo quanto ay en España y en las Yndias, que no carecen de cosa ninguna; los precios de todo son tan moderados, que casi todo es de balde; traen asimismo cantidad de artillería de bronze muy bien labrada y todo género de municiones... ${ }^{8}$

Una década después de este relato, los chinos en Manila sobrepasaron los 5000 habitantes, y se constituyó así el primer barrio chino, llamado Parián de Manila. ${ }^{9}$ A los chinos se les llamó "sangleys" o "sangleyes", tal vez porque la expresión china

${ }^{6}$ Dolors Folch, "Un testimonio infravalorado: la China Ming en las relaciones castellanas del siglo Xvi”, Boletín Hispánico Helvético, núm. 21, primavera de 2013, p. 49.

7 Ollé, La empresa de China, op. cit., pp. 20-21.

${ }^{8}$ Juan de Maldonado Pacheco, "Carta en relación de Juan de Maldonado tocante al viaje y población de la isla de Luzón en Filipinas que emprendió Martín de Goyti por mandado del Gobernador de la Isla de Panae en aquel pays, López de Legázpi, Rio de Panay, 6 de mayo de 1572”, Archivo General de Indias, Patronato 24, ramo 14.

${ }^{9}$ Manel Ollé, "La proyección de Fujian en Manila: los sangleyes del Parián y el comercio de la Nao de China”, en Salvador Bernabéu Albert y Carlos Martínez Shaw (eds.), Un océano de seda y plata: el universo económico del Galeón de Manila, Sevilla, Consejo Superior de Investigaciones Científicas, 2013, pp. 155-178. 
shanglai 商来 significa "los venidos a comerciar", o changlai 常来 “los que vienen con frecuencia”. ${ }^{10}$

El proyecto español misional y militar en China se transformó, entonces, en un encuentro diplomático y mercantil en un mundo chino más allá de las fronteras imperiales y regido según la dinámica relacional sino-sureste asiática (filipina). La estrategia pasó De la Armada Invencible al galeón de Manila (Ollé). ${ }^{11}$ Manila se constituyó en una próspera y mercantil sociedad china de ultramar, y se ganó la reputación de "Perla de Oriente".

La presencia española, repartida en el archipiélago a través de las parroquias y los mandos militares, continuó interactuando entre las culturas malaya, musulmana y china, principalmente por temas de aduana e intereses comerciales. Los chinos crearon barrios y mercados de frutas, pescado seco, rollos de tela, arroz y aceites. Algunos tenían acceso a la seda y las codiciadas especias. Se casaban con mujeres malayas o tagalas, y algunos adoptaron enseñanzas cristianas y criaron hijos mestizos que finalmente colaboraron en los negocios y la política española. ${ }^{12}$ Los españoles criollos, por su parte, históricamente tuvieron privilegios legales y de dominio de las oficinas administrativas coloniales y altos cargos eclesiales. En esta sociedad en evolución, las comunidades asiáticas y mestizas construyeron una economía comercial que transformó la faz cultural de Filipinas.

A inicios del siglo XVII, la comunidad china de Manila ascendió a las 30000 personas, por lo que, sutilmente, al final, los españoles fueron los "conquistados". Incapaces de desarrollar la tradicional dinámica colonial agraria y minera, terminaron insertándose en la dinámica comercial del Sudeste Asiático y, al igual que los chinos, en una suerte de diáspora mercantil. La gran cantidad de chinos participantes de las redes de producción artesanal y de mercado marginó de las dinámicas comerciales

${ }^{10}$ Ch'en Ching-Ho, The Chinese Community in the Sixteenth Century Philippines, Tokio, The Centre for East Asian Cultural Studies, 1968, pp. 36-37.

${ }^{11}$ Ollé, La empresa de China, op. cit., pp. 231-236.

${ }_{12}$ Birgit Tremml-Werner, "The Global and the Local: Problematic Dynamics of the Triangular Trade in Early Modern Manila”, Journal of World History, vol. 23, núm. 3, septiembre de 2012, pp. 555-586. 
a los naturales de Filipinas. El intenso y creciente intercambio económico y cultural hizo de Manila una sociedad plural y multicultural, pero no ausente de mecanismos de marginalidad y control social de parte de las instituciones coloniales.

Este panorama tampoco significó el olvido de la Misión China. Más bien, y como se indicó, Filipinas se consolidó en la plataforma del proyecto misional. ${ }^{13}$ Esto se observa en dos funciones: el envío de embajadas misionales a China y, ante la imposibilidad de cruzar las fronteras imperiales, los trabajos realizados en una sociedad china de ultramar en lo que podría denominarse la Misión Sangley.

\section{III}

Con la conquista de las islas Filipinas, los españoles intentaron imponer una nueva cultura, estableciendo los clásicos asentamientos coloniales organizados alrededor de plazas e iglesias. La mayoría fueron fortificadas por muros de mampostería y se dividieron en cuatro partes designadas para distintos rangos sociales y étnicos y de confesiones religiosas. En el diseño se materializó la idiosincrasia española que gobernaba a través de un virrey distante con órdenes paralelas para los funcionarios políticos o religiosos. A medida que los nativos se allegaron bajo la autoridad de un fraile, vinieron las conversiones y las jurisdicciones para organizar las demandas coloniales de bienes y servicios.

La dominación política y religiosa de ningún modo fue segura. Dejando de lado los desafíos sangleyes -o chinos- y la lucha por dar cabida a la diversidad económica (cultivos) y cultural (religiones), el español también se enfrentó a la resistencia local. Por ejemplo, cuando los agustinos organizaron

${ }^{13}$ De hecho, es común encontrar discursos como el del misionero franciscano Marcelo de Ribadeneira, quien en el año 1601 señalaba: "todos los religiosos que pasaron y pasan a las Filipinas van con grandísimo deseo de entrar a evangelizar a Cristo crucificado a los idólatras del gran reino de la China". Marcelo de Ribadeneira, Historia de las islas del archipielago, y reynos de la gran China, Tartaria, Cuchinchina, Malaca, Sian, Camboxa y Jappon: $Y$ de lo sucedido en ellos a los religiosos descalcos, de la orden del seraphico padre San Francisco, de la prouincia de San Gregorio de las Philippinas, Barcelona, Empresa de Gabriel Graells y Giraldo Dotil, 1601, p. 109. 
bases misioneras, se consideraron esenciales los pueblos fortificados para tener éxito en el mantenimiento de las poblaciones musulmanas que se establecieron a través de generaciones de marinos, comerciantes y maestros árabes y malayos. Las luchas por la fe, las luchas de supervivencia del grupo, las redes comerciales asiáticas, así como la influencia musulmana en las comunidades chinas y etnomixtas se reformularon bajo el dominio de la Corona española. Las autoridades reales fueron recompensadas con ventajas fiscales y concesiones de tierras a cambio de mantener el orden y la prestación de adoctrinamiento religioso. $^{14}$

El alcance de cierta estabilidad colonial en el archipiélago filipino les permitió a las autoridades españolas retomar su objetivo original y razón principal de expansión: China. Pronto darían inicio las embajadas misionales. En el cuadro 1 se enumeran antes del establecimiento formal de misiones en China bajo el patronato español.

Estas embajadas misionales, como era de esperarse, en línea con el espíritu de cruzada característico de la expansión española de esta etapa de la modernidad, vinieron acompañadas de otra clase de objetivos, los comerciales, como la adjudicación de un puerto enclave en la costa china a imagen del Macao portugués obtenido en 1557 y las estratégico-militares de recopilación de información sobre el Imperio chino, que siempre matizaron el objetivo misional de obtener garantías chinas para la libertad de predicación.

Por otra parte, el cuadro 1 muestra que las embajadas misionales se dirigieron a ciudades portuarias del sur de China, situación que se explica más allá de la simple cercanía a Filipinas. Estas ciudades formaron parte de un mundo surasiático de redes comerciales y movimientos migratorios como los que dieron origen a la comunidad sangley en Filipinas. Esta situación, además, subraya la propuesta sobre el desarrollo de un espacio portuario chino partícipe de dinámicas suprarregionales más allá de las fronteras imperiales.

${ }^{14}$ John Leddy Phelan, "Pre-Baptismal Instruction and the Administration of Baptism in the Philippines during the Sixteenth Century", The Americas, vol. 12, núm. 1, julio de 1955, pp. 3-23. 


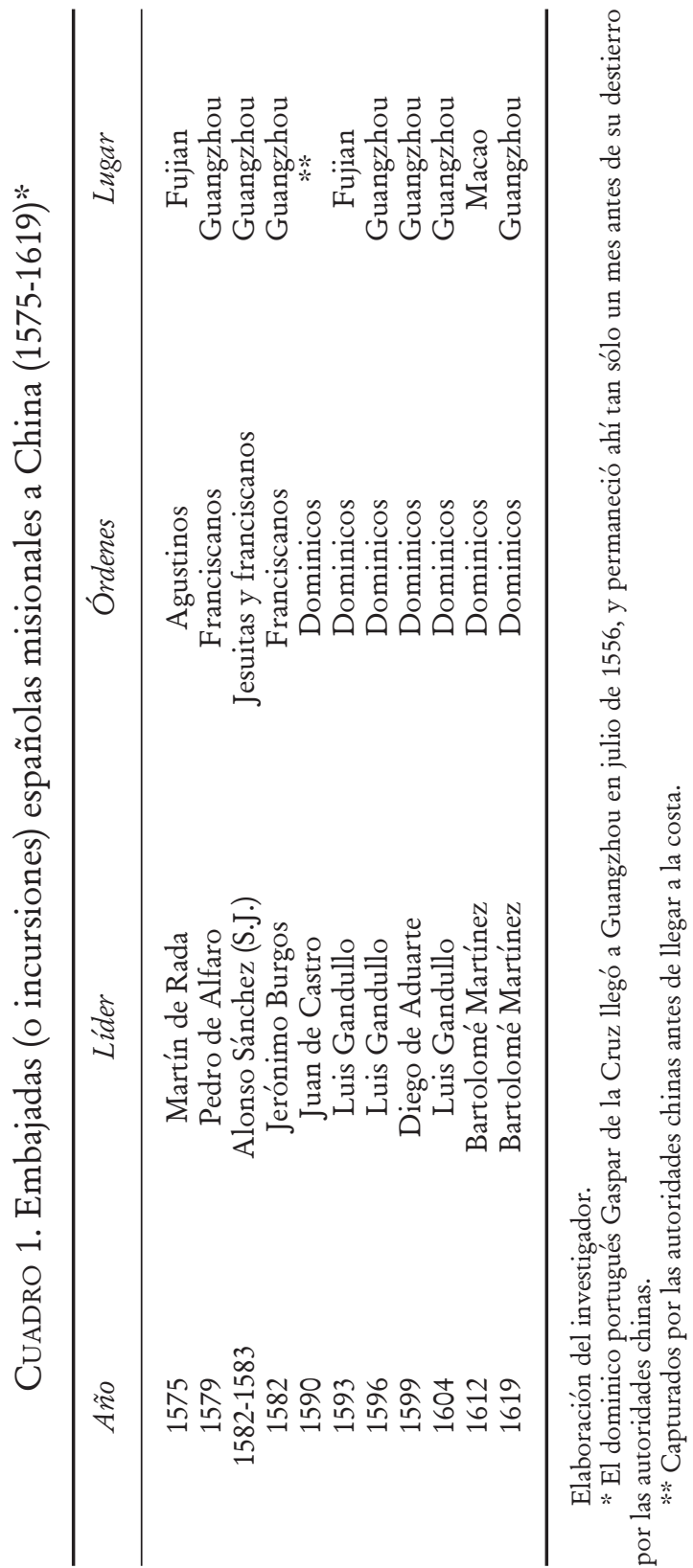


La primera embajada se desarrolló en $1575 .{ }^{15}$ El 8 de abril de ese año llegó a Manila el mandatario chino Wang Wanggao 王望高 y lo recibió Guido de Lavezaris, gobernador interino debido a la muerte de Legazpi. Esta oportunidad debía aprovecharse, por lo que Lavezaris, a sabiendas de los problemas de piratería atravesados por las autoridades chinas, se comprometió a capturar al famoso pirata Limahong, o Ling Feng 林鳳, y a entregarlo vivo o muerto. ${ }^{16}$ Además, le entregó a unas mujeres chinas liberadas por los españoles luego del enfrentamiento con susodicho pirata durante la batalla de Pangasinán en marzo de 1575. Este compromiso facilitó a los españoles un permiso para la primera embajada en China, cuyo principal objetivo consistió en obtener un enclave comercial en Fujian.

El 2 de junio de 1575, Wang regresó a China con la embajada española liderada por Miguel de Loarca y Pedro Sarmiento. La embajada incluyó soldados, encomenderos y a los misioneros agustinos Martín de Rada y Jerónimo Marín. El plan de Lavezaris consistía en obtener un permiso de residencia para los dos misioneros y que, luego de la negociación del enclave, el resto de la embajada regresara a Manila. El 5 de julio llegaron al puerto de Xiamen y, a los dos días, a Tong'an, ciudad al norte de la bahía, la cual los conectó mediante canales de ríos hasta Fujian, donde un mandatario llamado Liu Yaohui 劉堯 誨 los recibió el 17 de julio. Este encuentro fue aprovechado por los agustinos para solicitar el permiso de residencia con los objetivos de predicar la religión y aprender la lengua y las costumbres. El gobernador les pidió tiempo para tramitar la solicitud ante las autoridades imperiales; de paso, el mismo procedimiento se siguió en la negociación portuguesa por la cesión de Macao en la costa de Guangdong; en su momento desde Malaca, ahora desde Manila.

${ }^{15}$ Ollé, La empresa de China, op. cit., pp. 56-72.

${ }^{16}$ Igawa Kenji, "At the Crossroads: Limahon and Wakō in Sixteenth-Century Philippines”, en Robert J. Antony (ed.), Elusive Pirates, Pervasive Smugglers: Violence and Clandestine Trade in the Greater China Seas, Hong Kong, Hong Kong University Press, 2010, pp. 73-84. Dolors Folch, "Piratas y flotas de China según los testimonios castellanos del siglo Xvi”, en Pedro San Ginés Aguilar (ed.), La investigación sobre Asia Pacífico en España, Granada, Universidad de Granada, 2007, pp. 267-286. 
Acerca del modo de negociación sino-europeo, y siguiendo a Manel Ollé, ${ }^{17}$ se pueden identificar cinco indicadores que apoyan la hipótesis planteada sobre el desarrollo de un espacio portuario chino durante esta época. Primero, el pragmatismo y la distancia de los acuerdos del marco legal imperial, ya que se realizaron a nivel provincial, lo que evidencia la autonomía y la discrecionalidad en el ejercicio del poder y la interpretación de las leyes del espacio portuario chino. Segundo, tanto portugueses como españoles fueron vistos por los chinos como una comunidad mercantil más, lo cual va en línea con la dinámica del mundo sino-surasiático, pero prueba el desinterés por notar los objetivos misionales europeos. Tercero, ambos acuerdos surgieron de una coyuntura política y económica donde la interacción con los europeos se tornaba beneficiosa. Cuarto, los acuerdos venían precedidos de acciones militares contra los wokou (piratas). Y quinto, en ambos casos, el papel europeo de intermediación económica permitiría la entrada de la tan apreciada plata y la conexión con rutas comerciales de largo alcance.

Sin embargo, una serie de acontecimientos llevó al fracaso de la embajada. Ling Feng logró huir del asedio español. Lavezaris murió y fue sustituido por Francisco de Sande, especialista en derecho canónico por las universidades de Salamanca y Sevilla, y quien no compartía las ideas de negociación de su predecesor y más bien impulsó - muy acorde con el crítico de Bartolomé de las Casas, el presbítero Juan Ginés de Sepúlvedael proyecto de conquista armada de China ${ }^{18}$ Sande justificó su política con los postulados del derecho divino (católico) de esos años e interpretó, además, la entrega de regalos a las autoridades chinas como un tributo de sumisión jerarquizada. Con Sande quedaron sepultados, al menos por un tiempo, el acuerdo y el entendimiento sino-español.

Esta primera embajada terminó, entonces, el 28 de octubre de 1575. Pero más allá del obvio fracaso, resaltan dos aspectos positivos para el desarrollo de la Misión China: la experiencia de

${ }_{17}$ Ollé, La empresa de China, op. cit., pp. 65-66.

${ }^{18}$ Ibid., pp. 72-84. 
interactuar con chinos en China y la consecuente redacción de textos sobre dicha situación. Loarca y Rada escribieron una relación cada uno. Relacion del viaje que hezimos a la China desde la ciudad de Manila y Relaçion Verdadera delascosas del Reyno de Taibin por otro nombre China, respectivamente. Por su parte, Marín fue una de las fuentes orales utilizadas por González de Mendoza.

Cuatro años después de estos acontecimientos se realizó la segunda incursión misional en China, pero esta vez fue dirigida por franciscanos. Esta orden había llegado a Filipinas en 1578 y fundado la provincia de San Gregorio, con la idea de hacer trabajos misionales en China, Japón y el resto de Asia Oriental. La expedición tuvo un carácter secreto e ilegal, ya que no consiguió permiso del gobernador filipino, e incluyó a los frailes Pedro de Alfaro, Agustín de Tordesillas, Sebastián de San Francisco (o de Baeza) y Juan Bautista Lucarelli de Pésaro. La llegada al territorio chino se dio el 21 de junio de 1579 , a través del estuario del Zhujiang o río de las Perlas, pero la expedición fue detenida en la ciudad de Guangzhou, donde los franciscanos fueron interrogados y luego confinados por semanas en un barco. Cuando lograron librarse, los misioneros fueron a Zhaoqing a entrevistarse con el dutang 都堂 o comisionado imperial de la provincia, quien les hizo regresar a Guangzhou con la orden expresa de salir del país. En este proceso murió De Baeza, en tanto que De Alfaro y Lucarelli salieron vía Macao, y De Tordesillas regresó a Manila. Los misioneros, al parecer, todavía no comprendían la dinámica relacional china, así que las puertas continuaron cerradas para los intereses de evangelización.

Al año siguiente (1580), Gonzalo Ronquillo de Peñalosa relevó a Sande en la gubernatura de las Filipinas. El cambio de gobernador trajo consigo las intenciones de una nueva embajada en China. Entre 1580 y 1581 se realizaron los preparativos para que ésta se presentara ante Wanli 万历, decimotercer emperador Ming. La embajada estaría dirigida por los agustinos Juan González de Mendoza, Francisco de Ortega y, nuevamente, Jerónimo Marín; Rada había fallecido dos años antes. Empero, desde Nueva España el proyecto se desestimó debido a los fantasmas del fracaso de las incursiones anteriores, la humillación 
ante la posibilidad de uno nuevo y las dificultades económicas y logísticas. ${ }^{19}$

En este contexto, la dinámica misional cambiaría con la llegada de los dominicos a las Filipinas. Primero con el primer obispo del archipiélago en 1581, el discípulo de Bartolomé de las Casas, Domingo de Salazar, quien arribó junto con el primer grupo de jesuitas, y, segundo, porque la jurisdicción en los trabajos con los sangleyes pasó de los agustinos a los dominicos cuando éstos llegaron en 1587. Al igual que los franciscanos, los dominicos fundaron su provincia en Filipinas, la Provincia del Santísimo Rosario, ${ }^{20}$ también con la idea de un proyecto misional para todo el este de Asia. ${ }^{21}$ Como los agustinos y los franciscanos, los dominicos tenían la mirada puesta en la Misión China; por algo Salazar escribió a Felipe II en 1590: "una de las razones que me mobieron á acetar este obispado fué saver que estavan estas yslas muy cerca de la China y que abía en ellas muchos naturales de aquel Reino que á ellas se abían benido á bivir". ${ }^{22}$

A pesar del arribo de los dominicos, pronto se organizó sin ellos una segunda embajada (o tercera incursión), liderada por un jesuita y con la participación sólo de franciscanos. Un factor clave para su realización fue la unión de las coronas española y portuguesa luego de las Cortes de Tomar en abril de 1581. En ellas, Felipe II prometió la independencia de la administración portuguesa y la separación de los imperios coloniales de ultramar. De igual manera, el ahora también Felipe I de Portugal les prohibió a sus súbditos de Goa, Macao y Manila la entrada a las regiones reservadas al país del cual no eran naturales. Aunque se vedó el comercio entre portugueses y españoles, la dinámica de intercambio de seda china por armas y municiones en-

${ }^{19}$ Ibid., pp. 84-88.

${ }^{20}$ En 1589, esta provincia se reconocía en el capítulo general celebrado en Venecia con el título: "Provincia de Nuestra Señora del Rosario en las Islas Filipinas" y "Provincia del Santísimo Rosario de Filipinas", mientras que siete años después (1596), en Valencia, apareció con el nombre de "Provincia del Santísimo Rosario de Filipinas".

${ }^{21}$ En 1588 se organizó el convento de Santo Domingo en Manila y llegaron a Japón en 1602, a la isla Hermosa (Taiwán) en 1626, a China en 1632 y a Tonkín en 1676.

22 Domingo de Salazar, "Carta-Relación de las cosas de la China y de los chinos del Parián de Manila, enviada al Rey Felipe II por Fr. Domingo de Salazar, O. P, primer obispo de Filipinas. Desde Manila, á 24 de junio, de 1590", Archivo General de Indias, Filipinas 74. 
tre Manila y Macao se convirtió en la tónica de estos años. ${ }^{23}$ Con este panorama revivieron las iniciativas españolas de controlar la especiería de las Molucas.

Ronquillo de Peñalosa solicitó datos de carácter militar a los portugueses en las Molucas y ordenó el acondicionamiento del puerto de Nueva Segovia en la región de Cagayán, al nordeste de la isla de Luzón, como base para futuras expansiones territoriales por el mundo Pacífico y el espacio portuario chino. Al mismo tiempo, envió una embajada a Macao, dirigida por el jesuita Alonso Sánchez, para que solicitara la sumisión portuguesa ante Felipe II. Los objetivos eran los mismos de la embajada anterior: establecer una misión, comercio y un puerto enclave, y la recopilación de información estratégica. ${ }^{24}$

$\mathrm{La}$ embajada la integraron 26 personas, entre misioneros (dos franciscanos se sumaron en Ilocos), marineros, intérpretes, un piloto y remeros naturales de las Filipinas. Salió de Manila el 14 de marzo de 1582, pero la poca precisión en la ruta los llevó hasta Zhelin, enclave fronterizo con Fujian en la costa de Guangdong. Allí se les escoltó a una base militar donde se les interrogó y se examinó e inventarió todo su cargamento, en un ambiente de mucha tensión debido a las barreras del idioma. Después se decidió enviarlos al puerto de Ningbó, en la costa de Zhejiang, adonde llegaron el 12 de abril y nuevamente fueron interrogados. En Ningbó se encontraron con un oficial que hablaba tagalo y, con su ayuda, lograron un permiso para continuar hasta Guangzhou. Tomaron el trayecto vía Haifeng y descansaron en Huizhou, donde volvieron los interrogatorios, pero finalmente llegaron a Guangzhou. ${ }^{25}$

En dicha ciudad hicieron entrega de las cartas del gobernador filipino al haidao 海道, especie de vicecomisario de las costas, identificado por Sánchez como la máxima autoridad de la ciudad. Este momento coincidió con uno de los dos viajes

${ }^{23}$ Charles Ralph Boxer, The Christian Century in Japan (1549-1650), Manchester, Carcanet Press, 1993, pp. 241-242.

${ }^{24}$ Ollé, La empresa de China, op. cit., pp. 89-96.

${ }_{25}$ Alonso Sánchez, "Relación breve de la jornada quel P. Alonso Sánchez de la Compañía de Jesús hizo por horden y parezer del SR. D. Gonzalo Ronquillo de Peñalosa, governador de Philipinas, y del Sr. obispo y oficiales de S.M. desde la Isla de Luzón y ciudad de Manila a los Reynos de la China”, Manila, abril-junio de 1583, Archivo General de Indias, Filipinas 79, 2, 15. 
anuales permitidos a los portugueses desde Macao. Entre los portugueses se encontraban otros jesuitas. Luego de la primera audiencia a los cuatro misioneros de la embajada española, se les trasladó a la residencia temporal del jesuita Michele Ruggieri, "líder" de la Misión China para ese momento y quien, junto con Matías Panela, realizaba la primera embajada macaense en territorio chino. A él, Sánchez le reveló los verdaderos objetivos de la embajada española. ${ }^{26}$ A los tres días volvieron los interrogatorios y los misioneros pasaron el filtro, pero aún debían esperar la resolución del dutang en Zhaoqing, un fujienés llamado Chen Rui 陳瑞, con el grado jinshi desde 1553, y uno de los primeros personajes en aparecer en el diario de Ricci al llegar a China. ${ }^{27}$

Sin embargo, los planes españoles se filtraron entre los portugueses y de ellos a Chen Rui, quien de inmediato ordenó el arresto de los miembros de la embajada (con excepción de los cuatro misioneros) y demandó la presencia de las autoridades de Macao para rendir explicaciones. En este contexto se nombró a Ruggieri nuevo obispo de Macao, y se le encomendó la negociación de la liberación de los españoles. Por su parte, Sánchez salió rumbo a Macao, adonde llegó entre el 29 y el 31 de mayo. Allí se encontró con Alessandro Valignano, visitador del obispado de Goa de la Compañía de Jesús en "las Indias portuguesas". Valignano regresaba de Nagasaki y se encontraba pronto a salir hacia Europa junto con cinco japoneses conversos. ${ }^{28}$

En julio de 1582, buscando evitar la persecución de las autoridades chinas, Sánchez huyó en secreto rumbo a Japón, pero un temporal hizo que la embarcación en que viajaba naufragara en la isla de Taiwán entre el 17 y el 21 julio, tiempo en que convivió con el jesuita portugués en Japón Francisco Pires. En ese momento, Taiwán se conocía, según las fuentes chinas Ming, como Dongfan o bárbaros del este, y Da Liuqiu, especie de archipiélago junto a Japón y a la isla Okinawa; según las portuguesas, como Ilha Formosa, y para las españolas

${ }^{26}$ Idem.

${ }^{27}$ Matteo Ricci, China in the Sixteenth Century: The Journals of Matthere Ricci, 1583-1610, trad. Louis Jouis Gallagher, Nueva York, Random House, 1953, pp. 135136.

${ }^{28}$ Ollé, La empresa de China, op. cit., pp. 96-109. 
era la isla Hermosa. Era un territorio no sinizado, con escasa presencia migratoria, escala habitual de juncos en el trayecto Fujian, Luzón, Borneo, Java, Sumatra y Malasia, y base de operaciones y puerto de esclavos de los wokou sino-japoneses. El 4 octubre de 1582 lograron construir una nueva embarcación y zarparon de regreso a Macao.

En Macao, Sánchez se enteró de una nueva incursión de una embajada misional española, liderada por el franciscano Jerónimo Burgos y conformada por 17 personas, entre misioneros y soldados, pero todos vestidos de franciscanos. ${ }^{29}$ Esta delegación salió de Manila el 21 de junio y se encontraba encarcelada en una prisión de Guangzhou desde hacía meses debido al enfado de las autoridades chinas por el engaño de la embajada anterior. Sánchez solicitó, entonces, a los jesuitas, a las autoridades civiles de Macao y al comerciante Bartolomeu Vaz Landeiro, ${ }^{30}$ la mediación con los chinos para liberar a los detenidos en Guangzhou, que ya sumaban 39 españoles entre las dos embajadas. Esto llevó a la conformación de una segunda embajada macaense a Zhaoqing en noviembre de 1582. Ésta fue encabezada por Panela e iba repleta de regalos, con lo que logró calmar los ánimos chinos y algunos éxitos, tal vez inesperados, para los intereses portugueses y jesuitas. No sólo se solucionaron los problemas ocasionados por las embajadas españolas anteriores (incluida la liberación de los 39 detenidos) y se consolidó Macao ante las autoridades chinas, sino que además Panela consiguió, por primera vez, un permiso de residencia en el interior del territorio chino para el establecimiento de una misión jesuita permanente en Zhaoqing. ${ }^{31} \mathrm{~A}$ ella, a los pocos meses, llegó un joven Ricci, y la historia del encuentro de China con los misioneros cambiaría para siempre. ${ }^{32}$

Finalmente, el 18 de diciembre de 1582, los portugueses de Macao juraron fidelidad a Felipe II. Para ello fue clave la intermediación de Valignano. Los portugueses sólo pusieron

${ }^{29}$ Ribadeneira, Historia de las islas del archipiélago..., op. cit., p. 110.

${ }^{30}$ Importante comerciante portugués en las rutas asiáticas desde Goa hasta Nagasaki, apodado por los japoneses como el Rey de los portugueses.

${ }^{31}$ Ollé, La empresa de China, op. cit., pp. 114-118.

${ }^{32}$ Ricardo Martínez Esquivel, “Xitai 西泰 o 'la Eminencia del Oeste' y su encrucijada al inventar a Deus en la mente de kongzi 孔子 a 2000 años de su muerte”, Revista de Lenguas Modernas, núm. 23, enero-junio de 2015, pp. 437-454. 
una condición: no más embajadas españolas a China o a Macao. Por otro lado, con la sumisión portuguesa, el imperio de la Casa de los Habsburgo ganó un punto clave en la ruta comercial Goa-Nagasaki.

El 27 de marzo de 1583, los miembros de las dos fallidas embajadas regresaron a Manila luego de una travesía (la primera al menos) de un año y dos semanas. ${ }^{33}$

El año de regreso de las antedichas delegaciones también incluyó un hecho importante para el desarrollo de la Misión Sangley. Una de las instituciones más lamentables de la historia del cristianismo, la Inquisición, llegó al Sudeste Asiático. Y si bien el Consejo de la Suprema Inquisición española no organizó un tribunal, estableció una comisaría en Manila, dependiente del Tribunal del Santo Oficio novohispano. ${ }^{34}$ Debido a las dificultades de comunicación entre Manila y Nueva España, esta comisaría llevó a cabo funciones de subtribunal. Los misioneros mendicantes y jesuitas en Manila tenían cierta autonomía en comparación con el clero secular, pero eso no significó que estuvieran exentos del patronazgo español y la justicia inquisitorial.

La comisaría de Manila, al igual que todos los tribunales españoles, no tenía la facultad de llevar asuntos indígenas, pues de éstos se responsabilizaba cada diócesis. ${ }^{35}$ ¿De quiénes, entonces, se ocupó en Filipinas? En su mayoría, de los chinos del Parián acusados principalmente de idólatras y supersticiosos ${ }^{36}$-representación común entre los misioneros mendicantes sobre la religiosidad china-, ${ }^{37}$ pero también de los musulmanes de Min-

${ }^{33}$ Ollé, La empresa de China, op. cit., pp. 119-120.

${ }^{34}$ José Toribio Medina, Historia del Tribunal del Santo Oficio de la Inquisición en México, México, Consejo Nacional para la Cultura y las Artes, 1991, p. 15.

${ }^{35}$ Solange Alberro, Inquisición y sociedad en México, 1571-1700, México, Fondo de Cultura Económica, 1988, p. 26.

${ }^{36}$ Gómez Pérez Dasmariñas, Cristóbal de Salvatierra y Alonso de Torres, "Un auto que apareció fijado en las puertas de Santo Domingo, firmado por Fray Cristóbal de Salvatierra, sobre la representación de comedias de los Chinos", febrero-marzo de 1592, Archivo General de Indias, Filipinas 6.

${ }^{37}$ Dolors Folch, "Antes del confucianismo. La religión china vista a través de los testimonios castellanos del siglo Xvı”, en Pedro San Ginés Aguilar (ed.), Nuevas perspectivas de investigación sobre Asia Pacífico, Granada, Universidad de Granada, 2008, pp. 195-210. 
danao y los sultanatos vecinos, ${ }^{38}$ así como de los piratas holandeses, ingleses y japoneses, y de los comerciantes armenios sujetos a causas de fe por no profesar el catolicismo. ${ }^{39}$

El trabajo con los chinos de Manila en la Misión Sangley, al igual que en el resto de las misiones cristianas alrededor del mundo, incluyó la imposición de la cultura española, como el cambio del nombre en el bautizo, el uso de vestimentas españolas o el corte de cabello - con el cual también se pretendía evitar su retorno al continente al suprimirse un rasgo de identidad-. Este tipo de represiones llevó a los chinos sangleyes a organizar rebeliones; como respuesta, los españoles ajusticiaron y exterminaron a varias decenas de miles de chinos durante el siglo XVII $(1603,1639,1662,1668) .{ }^{40}$

Acerca de estas masacres, Manel Ollé explica la producción a posteriori de los siguientes tres mismos acontecimientos. Primero, debido a la importancia de la comunidad sangley en Filipinas para la economía española, se buscaron maneras de repoblar el Parián. Segundo, a pesar de los riesgos de una nueva matanza, el Parián se repoblaba rápidamente con comerciantes e inmigrantes chinos. En estas dos situaciones se observa la presión migratoria de Fujian y el atractivo mercantil de Manila. Y tercero, no obstante que estas masacres eran del conocimiento de las autoridades chinas, no hubo ninguna iniciativa de venganza o intervención. ${ }^{41} \mathrm{El}$ argumento de Ollé es destacable, ya que apoya la hipótesis propuesta de un espacio portuario chino y la consecuente expansión de un mundo chino más allá de las fronteras imperiales y específicamente en el Sudeste Asiático.

${ }^{38}$ Antes de la llegada de los españoles al Sudeste Asiático, el islam había arribado a las islas de la actual Indonesia y, en el momento en que penetró en Mindanao, el cristianismo lo hizo en Cebú y Luzón. Por consiguiente, el archipiélago filipino atestiguó una nueva lucha española de "moros y cristianos". Ostwald Sales Colín, El movimiento portuario de Acapulco. El protagonismo de Nueva España en la relación con Filipinas, 1587-1648, México, Plaza y Valdés, 2000, p. 46.

${ }^{39}$ Medina, Historia del Tribunal..., op. cit., p. 263. F. Delor Angeles, “The Philippine Inquisition: A Survey”, Philippine Studies, vol. 28, núm. 3, cuarto trimestre de 1980, pp. 253-283.

${ }_{40}$ Manel Ollé, "La formación del Parián de Manila: la construcción de un equilibrio inestable", en San Ginés Aguilar (ed.), La investigación sobre Asia Pacífico en España, op. cit., pp. 28-29.

${ }^{41}$ Ibid., p. 46. 
Pero no todo en la Misión Sangley consistió en Inquisición y masacres. Los frutos del trabajo misional pueden ser valorados en términos religiosos, culturales y económicos. Por ejemplo, paulatinamente aumentó el número de bautizados registrados. ${ }^{42} \mathrm{La}$ estrategia consistió en aprender la lengua china, ${ }^{43}$ incluidas sus variantes fujianesas (habla de los sangleyes). Como consecuencia, hubo una importante producción de literatura con propósitos evangelizadores, como catecismos y tratados teológicos, pero también gramáticas y vocabularios. En este contexto sobresalió la primera traducción de un texto chino a una lengua europea viva (castellano), el Mingxin baojian 明 心宝鉴 (conjunto de citas de libros clásicos), traducido por el dominico Juan Cobo.

El dominio de la lengua china les proporcionó a los misioneros una llave de acceso a las redes sociales chinas, en particular a las comerciales, del Sudeste Asiático hasta Fujian. De hecho, al parecer, el mismo gobernador filipino Santiago de Vera se preocupó por la cristianización de los sangleyes y les proporcionó instructores chinos a los misioneros. ${ }^{44} \mathrm{De}$ acuerdo con José Antonio Cervera, esta preocupación entre los misioneros mendicantes de aprender la lengua china es un claro precedente de la estrategia jesuita de acomodación. ${ }^{45}$ Estas órdenes, en lo referente a lo que Ricci y sus sucesores jesuitas harían después, no tienen nada que envidiarles; los agustinos tuvieron a Rada, y los dominicos, además de Cobo, a Miguel de Benavides, sobre quienes el obispo de Salazar llegó a señalar que "los dos an aprendido tan bien la lengua de los sangleyes, y el uno las letras de su lengua, ques la cosa más dificultosa que en ella ay, que los sangleyes están maravillados de lo que save". 46

${ }^{42}$ Diego de Aduarte [1640], Historia de la provincia del Rosario de la Orden de Predicadores, en Filipinas, Japón y China, Madrid, Consejo Superior de Investigaciones Científicas, 1962, vol. 1, p. 187. Sales Colín, El movimiento portuario..., op. cit., p. 48.

${ }_{43}$ Ricardo Martínez Esquivel y Pablo Rodríguez, "Entre la religiosidad china y el evangelio cristiano: ¿una mirada a la 'otra' primera divergencia?", Revista Estudios, núm. 32, 2016, pp. 518-557.

${ }^{44}$ Albert Chan, "A Note on the Shih-lu of Juan Cobo", Philippine Studies, vol. 37, núm. 4, cuarto trimestre de 1989, p. 481.

${ }^{45}$ Cervera, Tras el sueño de China, op. cit., p. 322.

${ }^{46}$ Salazar, "Carta-Relación de las cosas...", op. cit. 
Además del aprendizaje de la lengua, la Misión Sangley se caracterizó por la organización de hospitales gratuitos, como en el caso de los franciscanos y los dominicos, que "trataron de hacer un hospital donde curar los enfermos pobres, que era mucho lo que padecían en tierra extraña, desamparados de todos, en la mayor necesidad, que es la enfermedad y la muerte". ${ }^{47}$ Igualmente, hubo una preocupación por la educación primaria y la enseñanza de oficios, como pintar, encuadernar, coser, y hasta de astrología. ${ }^{48}$

Regresando a las embajadas misionales o, mejor dicho, a los intentos de incursión en China, antes de finalizado el siglo XVI, como se observa en el cuadro 1, hubo cuatro más $(1590,1593,1596$ y 1599) y todos por parte de dominicos. En el primero los misioneros terminaron encarcelados en Haiteng hasta su destierro a Manila, y en los otros tres lo mismo, pero en Guangzhou. ${ }^{49}$ El cambio de siglo no trajo mayor suerte y, más bien, tras la masacre de 1604, un Ricci ya instalado en China encendió las luces de alarma, pero, como se explicó líneas arriba, siguiendo a Ollé, luego de una embajada en ese mismo año,

[...] negociaron bien con el Virrey de la provincia de Chincheo [Quanzhou, Fujian], que es de donde vienen los chinos a Manila; y habiéndoles dado licencia para comprar muchas municiones para su ciudad, los despidió prometiendo continuar con el trato, como lo hizo, pues el año siguiente vinieron trece navíos, y de allí adelante se fue continuando, como si nada de lo dicho hubiera ocurrido. ${ }^{50}$

Años después de estos acontecimientos, un nuevo hecho transformó la dinámica de la Misión China. En 1608, el papa Pablo V autorizó a todas las órdenes misioneras la incursión para trabajos de evangelización en China y Japón, con libertad de elegir la ruta de ingreso. Esto terminó con el monopolio jesuita y la necesidad de acudir al padroado portugués, pero acentuó la competencia y el enfrentamiento entre las órdenes y los imperios marítimos por la llegada al Reino del Centro.

${ }^{47}$ Aduarte, Historia de la provincia..., op. cit., vol. 1, pp. 218-219.

${ }^{48}$ Ibid., p. 219.

${ }^{49}$ José María González, Historia de las Misiones dominicas en China, Madrid, Imprenta Juan Bravo 3, 1964, vol. 1, pp. 37 y ss.

${ }^{50}$ Aduarte, Historia de la provincia..., op. cit., vol. 1, p. 431. 
Como hasta el momento sucedió, la Misión China nunca se desenvolvió como un proyecto unido y coherente del catolicismo.

Hubo dos intentos más de incursión desde Manila, ambos liderados por el dominico Bartolomé Martínez, en 1612 y 1619, mas al parecer este camino estaba destinado al fracaso. Entonces, se buscaron nuevas rutas. Se probó vía Corea en 1618, pero los misioneros fueron detenidos en su escala en el puerto japonés de Nagasaki. ${ }^{51}$ No obstante, una nueva posibilidad surgió: Taiwán, aunque el imperialismo español no era el único que estaba tras esta isla, pues un nuevo actor había emergido surcando las aguas orientales del mundo Pacífico: los holandeses.

En 1588, debido a la guerra española con holandeses e ingleses y el consecuente desastre de la Armada española, hubo un declive de la influencia española en el mundo Pacífico. Esto permitió la incursión de los comerciantes holandeses, quienes en 1602 organizaron lo que podría considerarse la primera corporación multinacional de la historia: la Compañía Neerlandesa de las Indias Orientales (Vereenigde Oostindische Compagnie) -vOC, por sus siglas en neerlandés-. Los barcos holandeses navegaron primero hasta Java, en la actual Indonesia (1596), e iniciaron las travesías de barcos cargados de maderas del bosque, café y añil y con planes de conquista comercial de las islas de las especias. Pronto, la voc se convirtió en la más importante potencia del archipiélago indonesio; sobrepasó a Batavia, principal centro comercial antes de su llegada. Empezaron el cultivo de extensas tierras por medio de alianzas con los sultanatos, y monopolizaron los acuerdos comerciales, exclusivos para los transportistas holandeses. ${ }^{52}$

Cargamentos chinos y una creciente población comerciante y mano de obra china ampliaron el intercambio regional y ayudaron a construir canales, vecindarios y fortificaciones. Poco a poco, los pueblos de bambú y techo de palma dieron paso a estructuras de madera reforzadas con piedra de cantera cincelada en ladrillos, azulejos y pavimentos. El personal de la

${ }^{51}$ González, Historia de las Misiones..., op. cit., vol. 1, p. 43.

${ }^{52}$ Ruurdje Laarhoven y Elizabeth Pino Wittermans, "From Blockade to Trade: Early Dutch Relations with Manila, 1600-1750”, Philippine Studies, vol. 33, núm. 4, cuarto trimestre de 1985, pp. 485-504. 
voc vivía dentro de las murallas de la ciudad de Batavia, acompañado por miembros de su familia y sirvientes. En los barrios cercanos se establecieron los mardijkers, mestizos resultado de las relaciones exogámicas de los holandeses con los nativos y las comunidades asiáticas cristianas. Por su parte, a los chinos de Batavia se les forzó a salir de la ciudad amurallada por discriminación étnica, lo que llevó a la construcción de un barrio chino, próspero hasta el día de hoy (2018), como centro comercial de restaurantes y mercados. ${ }^{53} \mathrm{Al}$ igual que en la comunidad española de Manila, donde las relaciones exogámicas y el desarrollo del mestizaje transformaron el paisaje de las comunidades y las culturas, en los centros urbanos holandeses y chinos se entretejieron relaciones con javaneses. Por ejemplo, las familias de Eurasia producto de matrimonios holandeses y javaneses, por lo general fueron cristianas, políglotas y pluriculturales en lo que respecta a comidas y vestimentas.

En 1624, la voc llegó a Taiwán; empero, los holandeses se establecieron sólo en el sur de la isla, por lo que en 1626, cuando llegaron los españoles, contaron con la parte norte para su conquista. La expedición militar española partió de Manila el 8 de febrero de 1626, con la participación de Bartolomé Martínez y otros cinco dominicos. Los españoles se establecieron en un lugar que llamaron la Santísima Trinidad, actual Keelung, y al poco tiempo fundaron conventos dominicos y franciscanos. $\mathrm{La}$ misión en Taiwán pronto alcanzó la tan deseada meta de las órdenes mendicantes de insertarse en el territorio chino.

Esta nueva colonia española permitió el desarrollo de una red que unió Manila, Taiwán, la costa de Fujian y el sur de Japón. Sin embargo, la negativa china a entablar relaciones con la Corona española; la resistencia de los sultanatos musulmanes en las Molucas y Mindanao; el imperialismo japonés, convertido en una amenaza latente para Filipinas, y el fortalecimiento de la presencia holandesa, llevaron a la expulsión de los españoles del territorio taiwanés en $1640 .{ }^{54}$ Pero la Misión China,

${ }^{53}$ Li Minghuan, "From 'Sons of the Yellow Emperor' to 'Children of Indonesian Soil': Studying Peranakan Chinese Based on the Batavia Kong Koan Archives", Journal of Southeast Asian Studies, vol. 34, núm. 2, junio de 2003, pp. 215-230.

${ }^{54}$ Manel Ollé, "Comunidades mercantiles en conflicto en los estrechos de 
en su dimensión mendicante, ya había iniciado dentro de las fronteras chinas.

En 1631, la primera embajada misional española salió de Taiwán rumbo a China. Liderada por los dominicos Ángel Cocchi y Tomás de la Sierra, se dirigió a Fujian con el objetivo de entrevistarse con el dutang, a quien se le presentaría como tributo una vajilla de plata. La suerte tampoco había cambiado mucho, en el camino fueron atacados por piratas y se perdieron los regalos. Pocos meses después, los piratas fueron capturados y la vajilla fue recobrada. Por su parte, los dominicos lograron llegar a la ciudad de Fuzhou, capital fujianesa donde ya había una misión dirigida por el jesuita italiano Giulio Aleni, y se entrevistaron con el dutang. Tras varios meses, como era la constante, se decidió expulsarlos, pero esta vez, en la embarcación en la que fueron deportados

[...] iba en aquel navío un japón cristiano, de algunos que andan derramados por la China, con deseo de irse a tierra de cristianos, que sabía muy bien la lengua mandarina. Trató, pues, con él el Padre Fr. Angel se vistiese su hábito, y se fingiese enfermo, y muy tapado se echase en parte escura del navío, como que lo hacía por guardarse del aire y del sereno, y no faltó quien ayudase a encubrirle, que semejantes casos corren por particular providencia de Dios, y con esto se quedó el Padre en tierra escondido, y las guardas que le llevaron a embarcar deslumbradas con la vista del fraile fingido, y como el viaje hasta Isla Hermosa era corto, pudo ir así desconocido hasta llegar allá. ${ }^{55}$

Tras seis meses con cierta discreción, Cocchi se trasladó a la ciudad de Fu'an, en el norte de Fujian. En julio de 1633, lo alcanzaron el dominico Juan Bautista Morales y el franciscano Antonio Caballero de Santa María; un año después, el dominico Francisco Díaz y el franciscano Francisco de la Madre de Dios, y en 1637, los dominicos Juan García y Pedro Chaves y los franciscanos Onofre Palleja, Francisco Escalona, Domingo Urquicio y Gaspar Alenda. ${ }^{56}$ En tan sólo seis años se logró lo que no se había podido en más de medio siglo (1565-1631). Una

Taiwán (1624-1684)", Revista de Historia Económica, vol. 23, núm. 1, marzo de 2005, pp. 275-297.

${ }_{55}$ Aduarte, Historia de la provincia..., op. cit., vol. 2, p. 365.

${ }^{56}$ Ibid., pp. 357-372. 
primera etapa de la Misión China llegó a su fin, y dio espacio a una nueva en que órdenes, imperios europeos de ultramar e intereses de todo tipo, se enfrentarían en detrimento del objetivo teórico de evangelizar el mundo chino.

¿Qué elementos contextuales caracterizaron el establecimiento de misiones mendicantes en el interior del territorio chino entre los siglos XVII y XVIII? ¿Cuáles serían los resultados de un análisis comparativo del establecimiento de misiones católicas, en términos de órdenes religiosas y provincias chinas? ¿En qué medida el espacio portuario chino condicionó el movimiento misionero en China? Teniendo en cuenta la experiencia jesuita, la más estudiada de todas, ¿qué similitudes y divergencias se identifican en la producción de la cultura, la literatura, el arte, las ideas, la teología, la religión y el comercio en los procesos de encuentro y esfuerzo de los misioneros por comprender el Reino del Centro? Éstas son algunas de las problemáticas por investigar a partir de la propuesta de análisis planteada en este ensayo.

\section{IV}

La Misión China se estableció como parte de una modernidad expansionista e imperialista. En términos generales, este proyecto funcionó como el espíritu y la justificación teórica de intereses de conquista y comercio. Los misioneros buscaron a toda costa insertarse socialmente en el mundo chino, aprendiendo el idioma, por ejemplo, y tal vez sin ser el objetivo principal, desarrollando la Misión Sangley (1565-1631) para los chinos de ultramar en el Sudeste Asiático y, en particular, el espacio colonial filipino. Pero no dejaron de ajustarse a los intereses políticos y económicos del poder que los patrocinaba. Esto último explica lo tardío (hasta 1631) y la forma en que se estableció la primera misión de una orden mendicante en territorio chino. Si bien hubo un interés por aprender la lengua y realizar trabajos con el fin de insertarse entre los chinos, como la enseñanza de oficios o los hospitales gratuitos, no se tuvo la visión de comprender la dinámica de relaciones establecida por el Imperio chino en Asia desde siglos antes de la llegada de los 
europeos. Con la Misión China llegó lo peor no sólo de los imperialismos europeos, sino también de la historia del cristianismo, como lo fue la Inquisición.

La investigación histórica sobre los roles de las órdenes mendicantes en la Misión China se encuentra en proceso de construcción. Paradigmas historiográficos, como la historia global o la prosopografía y el análisis de redes sociales, ofrecen ventanas distintas a los estudios sobre los jesuitas, y únicas para la comprensión de la Misión China. Además, los escasos estudios históricos sobre este tema han quedado marginados de los proyectos historiográficos y lo poco realizado se formula y difunde de manera aislada. Por consiguiente, se considera clave que, para que los papeles desempeñados por las órdenes mendicantes en la Misión China se desarrollen como tema historiográfico, el investigador descubra la utilidad de éstos como fuente complementaria a la comprensión de la historia de los encuentros, las relaciones y los contactos culturales y del poder.

Dirección institucional del autor:

Sección de Historia de la Cultura/Estudios Generales

Universidad de Costa Rica

243-2300 San José, Costa Rica

\section{Fuentes}

Aduarte, Diego de [1640], Historia de la provincia del Rosario de la Orden de Predicadores, en Filipinas, Japón y China, 2 vols., Madrid, Consejo Superior de Investigaciones Científicas, 1962.

"Copia de vna carta venida de Seuilla a Miguel Saluador de Valencia.

La qual narra el venturoso descubrimiento que los Mexicanos han hecho, nauegando con la armada que su Magestad mando hazer en Mexico. Con otras cosas marauillosas, y de gran prouecho para la Christiandad; son dignas de ser vistas y leydas", en $\mathrm{Pa}-$ tricio Hidalgo Nuchera (ed.), Los primeros de Filipinas. Crónicas de la conquista del archipiélago, Madrid, Miraguano Ediciones/ Ediciones Polifemo, 1995, pp. 210-212.

Gómez Pérez, Dasmariñas, Cristóbal de Salvatierra y Alonso de Torres, "Un auto que apareció fijado en las puertas de Santo 
Domingo, firmado por Fray Cristóbal de Salvatierra, sobre la representación de comedias de los Chinos", febrero-marzo de 1592, Archivo General de Indias, Filipinas 6.

GonzÁlez, José María, Historia de las Misiones dominicas en China, vol. 1, Madrid, Imprenta Juan Bravo 3, 1964.

Maldonado Pacheco, Juan de, "Carta en relación de Juan de Maldonado tocante al viaje y población de la isla de Luzón en Filipinas que emprendió Martín de Goyti por mandado del Gobernador de la Isla de Panae en aquel pays, López de Legázpi, Rio de Panay, 6 de mayo de 1572”, Archivo General de Indias, Patronato 24, ramo 14.

Ribadeneira, Marcelo de, Historia de las islas del archipielago, y reynos de la gran China, Tartaria, Cuchinchina, Malaca, Sian, Camboxa y Jappon: $Y$ de lo sucedido en ellos a los religiosos descalcos, de la orden del seraphico padre San Francisco, de la prouincia de San Gregorio de las Philippinas, Barcelona, Empresa de Gabriel Graells y Giraldo Dotil, 1601.

RiccI, Matteo, China in the Sixteenth Century: The Journals of Matthew Ricci, 1583-1610, trad. Louis Jouis Gallagher, Nueva York, Random House, 1953.

Salazar, Domingo de, "Carta-Relación de las cosas de la China y de los chinos del Parián de Manila, enviada al Rey Felipe II por Fr. Domingo de Salazar, O. P, primer obispo de Filipinas. Desde Manila, á 24 de junio, de 1590”, Archivo General de Indias, Filipinas 74.

SÁNcheZ, Alonso, "Relación breve de la jornada quel P. Alonso Sánchez de la Compañía de Jesús hizo por horden y parezer del SR. D. Gonzalo Ronquillo de Peñalosa, governador de Philipinas, y del Sr. obispo y oficiales de S.M. desde la Isla de Luzón y ciudad de Manila a los Reynos de la China”, Manila, abril-junio de 1583, Archivo General de Indias, Filipinas 79, 2, 15.

\section{Bibliografía}

Alberro, Solange, Inquisición y sociedad en México, 1571-1700, México, Fondo de Cultura Económica, 1988.

Angeles, F. Delor, “The Philippine Inquisition: A Survey”, Philippine

Studies, vol. 28, núm. 3, cuarto trimestre de 1980, pp. 253-283.

BOXer, Charles Ralph, The Christian Century in Japan (1549-1650), Manchester, Carcanet Press, 1993. 
Cervera, José Antonio, Tras el sueño de China. Agustinos y dominicos en Asia Oriental a finales del siglo XVI, Madrid, Plaza y Valdés, 2013.

Chan, Albert, "A Note on the Shih-lu of Juan Cobo", Philippine Studies, vol. 37, núm. 4, cuarto trimestre de 1989, pp. 479-487.

ChIng-Ho, Ch'en, The Chinese Community in the Sixteenth Century Philippines, Tokio, The Centre for East Asian Cultural Studies, 1968.

Descalzo Yuste, Eduardo, “'Las misiones más trabajosas, y difíciles, que tiene la universal Compañía'. Dificultades de la labor misional de la Compañía de Jesús en Filipinas (1581-1768)”, Revista Estudios, núm. 32, 2016, pp. 467-495.

Folch, Dolors, "Antes del confucianismo. La religión china vista a través de los testimonios castellanos del siglo Xvi", en Pedro San Ginés Aguilar (ed.), Nuevas perspectivas de investigación sobre Asia Pacifico, Granada, Universidad de Granada, 2008, pp. 195-210.

Folch, Dolors, "Piratas y flotas de China según los testimonios castellanos del siglo Xvi", en Pedro San Ginés Aguilar (ed.), La investigación sobre Asia Pacífico en España, Granada, Universidad de Granada, 2007, pp. 267-286.

Folch, Dolors, "Un testimonio infravalorado: la China Ming en las relaciones castellanas del siglo xvı", Boletín Hispánico Helvético, núm. 21, primavera de 2013, pp. 41-69.

KenjI, Igawa, "At the Crossroads: Limahon and Wakō in SixteenthCentury Philippines", en Robert J. Antony (ed.), Elusive Pirates, Pervasive Smugglers: Violence and Clandestine Trade in the Greater China Seas, Hong Kong, Hong Kong University Press, 2010, pp. 73-84.

LaARHoven, Ruurdje y Elizabeth Pino Wittermans, "From Blockade to Trade: Early Dutch Relations with Manila, 1600-1750", Philippine Studies, vol. 33, núm. 4, cuarto trimestre de 1985, pp. 485-504.

Martínez Esquivel, Ricardo, “Xitai 西泰 o 'la Eminencia del Oeste' y su encrucijada al inventar a Deus en la mente de kongzi 孔子 a 2000 años de su muerte”, Revista de Lenguas Modernas, núm. 23, enero-junio de 2015, pp. 437-454.

MARTínez Esquivel, Ricardo y Pablo Rodríguez, "Entre la religiosidad china y el evangelio cristiano: cuna mirada a la 'otra' primera divergencia?”, Revista Estudios, núm. 32, 2016, pp. 518-557.

Medina, José Toribio, Historia del Tribunal del Santo Oficio de la Inquisición en México, México, Consejo Nacional para la Cultura y las Artes, 1991. 
Minghuan, Li, "From 'Sons of the Yellow Emperor' to 'Children of Indonesian Soil': Studying Peranakan Chinese Based on the Batavia Kong Koan Archives", Journal of Southeast Asian Studies, vol. 34, núm. 2, junio de 2003, pp. 215-230.

Numhauser, Paulina, "El Real Patronato en Indias y la Compañía de Jesús durante el período filipino (1580-1640). Un análisis inicial”, Boletín Americanista, núm. 67, 2013, pp. 85-103.

Ollé, Manel, "Comunidades mercantiles en conflicto en los estrechos de Taiwán (1624-1684)”, Revista de Historia Económica, vol. 23, núm. 1, marzo de 2005, pp. 275-297.

Ollé, Manel, La empresa de China. De la Armada Invencible al galeón de Manila, Barcelona, Acantilado, 2002.

Ollé, Manel, "La formación del Parián de Manila: la construcción de un equilibrio inestable”, en Pedro San Ginés Aguilar (ed.), La investigación sobre Asia Pacifico en España, Granada, Universidad de Granada, 2007, pp. 27-49.

OlLÉ, Manel, "La proyección de Fujian en Manila: los sangleyes del Parián y el comercio de la Nao de China”, en Salvador Bernabéu Albert y Carlos Martínez Shaw (eds.), Un océano de seda y plata: el universo económico del Galeón de Manila, Sevilla, Consejo Superior de Investigaciones Científicas, 2013, pp. 155-178.

Pastells, Pablo, "Intentos y conquistas en el Extremo Oriente y competencias habidas con los portugueses sobre la posesión de las regiones situadas fuera del empeño, antes de la unión de las dos Coronas", ponencia presentada en el II Congreso de Historia y Geografía Hispanoamericanas, Sevilla, 1921.

Phelan, John Leddy, "Pre-Baptismal Instruction and the Administration of Baptism in the Philippines during the Sixteenth Century", The Americas, vol. 12, núm. 1, julio de 1955, pp. 3-23.

SAles Colín, Ostwald, El movimiento portuario de Acapulco. El protagonismo de Nueva España en la relación con Filipinas, 1587-1648, México, Plaza y Valdés, 2000.

Tremml-Werner, Birgit, "The Global and the Local: Problematic Dynamics of the Triangular Trade in Early Modern Manila", Journal of World History, vol. 23, núm. 3, septiembre de 2012, pp. 555-586. 
